RESEARCH PAPER

\title{
Smoking behaviour in Taiwan, 2001
}

C-P Wen, D T Levy, T Yuan Cheng, C C Hsu, S P Tsai

Tobacco Control 2005;14(Suppl I):i51-i55. doi: 10.1136/tc.2004.008011

See end of article for authors' affiliations .....................

Correspondence to: Chi Pang Wen, National Health Research Institutes, 35 Keyan Road, Zhunan Town, Miaoli County, Taiwan 350; Cwengood@ nhri.org.tw

\begin{abstract}
Purpose: To examine smoking behaviours in Taiwan and compare those behaviours to those in the USA. Methods: Using the National Health Interview Survey (NHIS) of Taiwan (2001), a survey of over 20000 participants, frequencies were calculated for smoking, ex-smoking, quantity smoked, and exposure to environmental tobacco smoke (ETS). Breakdowns by age, sex, and socioeconomic status were also calculated.

Results: The ratio of male to female smoking rates was 10.9 to 1 among adults $(46.8 \% / 4.3 \%)$, but 3.6 to 1 among underage teenagers (14.3\%/4.0\%). The proportion of underage to adult smokers was three times higher for girls than for boys. Smoking prevalence substantially increased during and after high school years, and peaked in those aged 30-39 years. Smoking rates of high school age adolescents increased more than threefold if they did not attend school or if they finished their education after high school. Low income and less educated smokers smoked at nearly twice the rate of high income and better educated smokers. The smoker/ex-smoker ratio was close to 7. Male daily smokers smoked on average 17 cigarettes/day, and females, 11. Half of the total population, especially infants and women of childbearing age, were exposed to ETS at home.

Conclusions: Taiwan has particularly high male smoking prevalence and much lower female prevalence. The low female prevalence is likely to increase if the current sex ratio of smoking by underage youth continues. The low quit rate among males, the high ETS exposure of females and young children at home, and the sharp increase in smoking rates when students leave school, are of particular concern. These observations on smoking behaviour can provide valuable insights to assist policymakers and health educators in formulating strategies and allocating resources in tobacco control.
\end{abstract}

In all, 6592 households (23473 persons) were sampled from the Taiwan area. Development of questionnaires was based on the Department of Health (DOH) needs of health indicators and the nature and nurture factors affecting health. The final version of the questionnaire was composed of five parts: household interview, individuals older than 12 years interview, individuals younger than 12 years interview, self administered questionnaire for teenagers between 12 and 17 years, and World Health Organization quality of life interview for adults aged 20 to 65 years.

Respondents were first asked whether they had smoked at least 100 cigarettes in their lifetime, and then asked whether they currently smoked. ${ }^{11}$ Those who smoked were asked if they currently smoked everyday, some days or not at all. Current smokers were also asked for the number of cigarettes they smoked on an average day. "Never smokers" were those who had not smoked 100 cigarettes in their lifetime. Individuals who had smoked 100 cigarettes in their lifetime were either a "current smoker" or "ex-smoker". Smokers were classified as "daily smokers" if they smoked every day in the last 30 days, "occasional smokers" if they smoked 1 to 29 of the last 30 days, and "ex-smokers" if they did not smoke in the last 30 days.

Estimates are also presented on the average number of cigarettes smoked per day by daily smokers. Data on the age of initiation were based on the question, "When did you begin to smoke regularly?". Initiation age for smokers age 18 or older was expressed as a median, using a birth cohort method. ${ }^{12}$

When NHIS interviewed 2540 adolescents aged 12-17, they were also given questionnaires to answer questions on aspects of health risk behaviour. The questionnaires were self administered in private and with confidentiality assured. Smoking rates are based on the same definitions as used with adults. 
Table 1 Adult smoking rates by age, education, profession and income $†$ in Taiwan, 2001

\begin{tabular}{|c|c|c|c|c|c|c|}
\hline & \multirow[b]{2}{*}{$\mathbf{n}$} & \multirow[b]{2}{*}{ Non-smoker } & \multirow[b]{2}{*}{ Ex-smoker } & \multicolumn{3}{|c|}{ Current smoker } \\
\hline & & & & Total & Someday & Daily \\
\hline \multicolumn{7}{|l|}{ Male } \\
\hline Ages 18 years and over (crude) & 7967 & $46.4(0.56)$ & $7.1(0.29)$ & $46.5(0.56)$ & $3.0(0.19)$ & $43.5(0.56)$ \\
\hline Ages 18 years and over (age adjusted) $\ddagger$ & & $46.4(0.56)$ & $6.8(0.28)$ & $46.8(0.56)$ & $3.1(0.19)$ & $43.7(0.56)$ \\
\hline \multicolumn{7}{|l|}{ Age } \\
\hline $18-19$ & 381 & $75.3(2.21)$ & $* 0.3(0.28)$ & $24.1(2.19)$ & $3.1(0.89)$ & $21.3(2.10)$ \\
\hline $20-29$ & 1750 & $53.8(1.19)$ & $1.7(0.31)$ & $44.5(1.19)$ & $4.2(0.48)$ & $40.3(1.17)$ \\
\hline $30-39$ & 1731 & $38.4(1.17)$ & $4.5(0.50)$ & $57.1(1.19)$ & $3.4(0.44)$ & $53.7(1.20)$ \\
\hline $40-49$ & 1648 & $41.5(1.21)$ & $6.9(0.62)$ & $51.6(1.23)$ & $2.9(0.41)$ & $48.7(1.23)$ \\
\hline $50-59$ & 1010 & $44.9(1.57)$ & $8.0(0.85)$ & $47.1(1.57)$ & $2.7(0.51)$ & $44.4(1.56)$ \\
\hline $60-69$ & 743 & $45.8(1.83)$ & $13.3(1.25)$ & $40.9(1.80)$ & $2.4(0.56)$ & $38.5(1.79)$ \\
\hline 70 or above & 704 & $46.6(1.88)$ & $22.9(1.58)$ & $30.5(1.74)$ & ${ }^{*} 0.7(0.31)$ & $29.8(1.72)$ \\
\hline \multicolumn{7}{|l|}{ Education ( $25-64$ years old) } \\
\hline Elementary (grade 6 or below) & 1123 & $39.8(1.46)$ & $7.8(0.80)$ & $52.4(1.49)$ & $2.0(0.42)$ & $50.4(1.49)$ \\
\hline Middle school (grade 7-9) & 1081 & $27.8(1.36)$ & $4.4(0.62)$ & $67.8(1.42)$ & $2.8(0.50)$ & $65.0(1.45)$ \\
\hline High school (grade 10-12) & 1795 & $36.7(1.14)$ & $6.1(0.56)$ & $57.2(1.17)$ & $3.7(0.45)$ & $53.5(1.18)$ \\
\hline College or above & 1616 & $60.3(1.22)$ & $5.7(0.58)$ & $34.0(1.18)$ & $4.0(0.49)$ & $30.0(1.14)$ \\
\hline \multicolumn{7}{|l|}{ Profession (25-64 years old) } \\
\hline White collar & 2529 & $49.2(0.99)$ & $6.0(0.47)$ & $44.8(0.99)$ & $4.2(0.40)$ & $40.6(0.98)$ \\
\hline Blue collar & 1368 & $33.4(1.28)$ & $5.4(0.61)$ & $61.2(1.32)$ & $2.8(0.45)$ & $58.4(1.33)$ \\
\hline Service industry & 467 & $39.6(2.26)$ & $3.9(0.90)$ & $56.5(2.29)$ & ${ }^{*} 2.1(0.66)$ & $54.4(2.30)$ \\
\hline \multicolumn{7}{|l|}{ Annual income (NT) (25-64 years old) } \\
\hline$\leqslant 240000$ (US\$6857) & 1523 & $37.4(1.24)$ & $6.6(0.64)$ & $56.0(1.27)$ & $2.4(0.39)$ & $53.6(1.28)$ \\
\hline$\leqslant 480000$ (US\$13714) & 1971 & $39.3(1.10)$ & $4.8(0.48)$ & $55.9(1.12)$ & $3.2(0.40)$ & $52.7(1.12)$ \\
\hline$\leqslant 960000$ (US\$27428) & 1804 & $47.1(1.18)$ & $7.2(0.61)$ & $45.7(1.17)$ & $3.6(0.44)$ & $42.1(1.16)$ \\
\hline$>960000$ (US\$27428) & 287 & $60.6(2.88)$ & $4.2(1.18)$ & $35.2(2.82)$ & $6.3(1.43)$ & $28.9(2.68)$ \\
\hline \multicolumn{7}{|l|}{ Female } \\
\hline Ages 18 years and over (crude) & 8154 & $95.3(0.23)$ & $0.5(0.08)$ & $4.2(0.22)$ & $0.6(0.09)$ & $3.6(0.21)$ \\
\hline Ages 18 years and over (age adjusted) $\ddagger$ & & $95.9(0.22)$ & $0.5(0.08)$ & $4.3(0.22)$ & $0.6(0.09)$ & $3.6(0.21)$ \\
\hline \multicolumn{7}{|l|}{ Age } \\
\hline $18-19$ & 342 & $95.9(1.07)$ & ${ }^{*} 0.3(0.30)$ & $3.8(1.03)$ & *1.2(0.59) & *2.6 (0.86) \\
\hline $20-29$ & 1798 & $95.3(0.50)$ & ${ }^{*} 0.2(0.11)$ & $4.5(0.49)$ & $0.7(0.20)$ & $3.7(0.45)$ \\
\hline $30-39$ & 1743 & $96.7(0.43)$ & ${ }^{*} 0.6(0.18)$ & $5.7(0.56)$ & $1.0(0.24)$ & $4.7(0.51)$ \\
\hline $40-49$ & 1721 & $95.9(0.48)$ & ${ }^{*} 0.2(0.11)$ & $3.8(0.46)$ & ${ }^{*} 0.4(0.15)$ & $3.4(0.44)$ \\
\hline $50-59$ & 1093 & $95.7(0.61)$ & ${ }^{*} 0.4(0.19)$ & $3.9(0.59)$ & ${ }^{*} 0.5(0.21)$ & $3.5(0.56)$ \\
\hline $60-69$ & 822 & $95.6(0.72)$ & ${ }^{*} 1.2(0.38)$ & $3.2(0.61)$ & ${ }^{*} 0.3(0.19)$ & $2.9(0.59)$ \\
\hline 70 or above & 635 & $96.4(0.74)$ & ${ }^{*} 1.1(0.41)$ & $2.5(0.62)$ & ${ }^{*} 0.3(0.22)$ & $2.2(0.58)$ \\
\hline \multicolumn{7}{|l|}{ Education (25-64 years old) } \\
\hline Elementary (grade 6 or below) & 1922 & $95.3(0.48)$ & ${ }^{*} 0.4(0.15)$ & $4.3(0.46)$ & ${ }^{*} 0.4(0.14)$ & $4.0(0.44)$ \\
\hline Middle school (grade 7-9) & 921 & $92.9(0.84)$ & ${ }^{*} 0.2(0.15)$ & $6.8(0.83)$ & ${ }^{*} 0.9(0.31)$ & $6.0(0.78)$ \\
\hline High school (grade 10-12) & 1785 & $93.8(0.57)$ & ${ }^{*} 0.6(0.19)$ & $5.6(0.54)$ & $1.1(0.24)$ & $4.5(0.49)$ \\
\hline College or above & 1249 & $98.1(0.39)$ & ${ }^{*} 0.4(0.18)$ & $1.5(0.35)$ & ${ }^{*} 0.2(0.14)$ & $1.3(0.32)$ \\
\hline \multicolumn{7}{|l|}{ Profession (25-64 years old) } \\
\hline White collar & 1935 & $95.6(0.47)$ & $* 0.5(0.16)$ & $3.9(0.44)$ & $0.7(0.19)$ & $3.2(0.40)$ \\
\hline Blue collar & 704 & $97.9(0.54)$ & - & $2.1(0.54)$ & ${ }^{*} 0.1(0.14)$ & $2.0(0.53)$ \\
\hline Service industry & 607 & $91.8(1.12)$ & ${ }^{*} 0.8(0.37)$ & $7.4(1.06)$ & *1.3 (0.46) & $6.1(0.97)$ \\
\hline \multicolumn{7}{|l|}{ Annual income (NT) (25-64 years old) } \\
\hline$\leqslant 240000$ (US\$6857) & 3544 & $95.1(0.36)$ & $0.5(0.11)$ & $4.4(0.34)$ & $0.6(0.13)$ & $3.8(0.32)$ \\
\hline$\leqslant 480000$ (US\$13714) & 1549 & $94.5(0.58)$ & ${ }^{*} 0.5(0.18)$ & $5.0(0.55)$ & ${ }^{*} 0.5(0.17)$ & $4.5(0.53)$ \\
\hline$\leqslant 960000$ (US\$27428) & 675 & $95.4(0.81)$ & ${ }^{*} 0.3(0.21)$ & $4.3(0.78)$ & ${ }^{*} 1.2(0.42)$ & $3.1(0.67)$ \\
\hline$>960000$ (US\$27428) & 71 & $98.6(1.40)$ & - & ${ }^{*} 1.4(1.40)$ & $-\quad 10-10.721$ & ${ }^{*} 1.4(1.40)$ \\
\hline
\end{tabular}

Individuals sampled in the NHIS were asked if anyone smoked in their home. Those who answered yes were asked how many days of the week someone smoked in their home. We tabulated the percentage of individuals exposed to smoke in their home and the extent of exposure based on the number of days.

\section{Statistical analyses}

Using SAS software, we calculated frequencies of the following outcome variables: daily and occasional smoking and ex-smoking rates, quantity smoked, and ETS exposure rates. Separate weights were not needed, because the sampling scheme led to a population profile that was tested to be very close to national average. ${ }^{13}$ The age adjusted estimates were almost identical to the non-adjusted prevalence in table 1 , reflecting that the age structure of the surveyed samples mirrored that of the national population.

Analyses of median initiation age were conducted by dividing the cross sectional survey data among ever-smokers into their respective years of birth. From 1901 to 1979, the initiation age (median) of each birth cohort, with years of birth grouped by five year interval, was calculated and plotted. ${ }^{12}$

\section{RESULTS}

\section{Smoking rates}

Age adjusted adult smoking prevalence in 2001 was $46.8 \%$ and $4.3 \%$, for males and females, respectively (table 1). For males, the smoking rate increased stepwise with age until age 40 , from $0.6 \%$ at 12 years old, to $17.3 \%$ by the beginning of high school (ages 15-16), to $22.6 \%$ by the end of high school (age 17), and then more than doubled to $47.7 \%$ by age 25 (table 2). The rate peaked at $57.1 \%$ during the $30-39$ years range, and reduced stepwise as age became older, but still $40.9 \%$ of those males aged 60-69 were smokers. Similar tendencies are shown for females, who peaked in their 30s and declined over later ages. 
Table 2 Youth smoking rates by age and by school attendance status in Taiwan, 2001

\begin{tabular}{|c|c|c|c|c|}
\hline \multirow[b]{3}{*}{ Age } & \multirow{3}{*}{$\begin{array}{l}\text { Female } \\
\text { All }\end{array}$} & \multicolumn{3}{|c|}{ Male } \\
\hline & & \multirow[b]{2}{*}{ All } & \multicolumn{2}{|c|}{ School attendance statust } \\
\hline & & & Yes & No \\
\hline 12 & $1.1 \%$ & $0.6 \%$ & - & - \\
\hline $13-14$ & $3.4 \%$ & $5.4 \%$ & - & - \\
\hline $15-16$ & $4.2 \%$ & $17.3 \%$ & $7 \%(199)$ & $47 \%(15)^{*}$ \\
\hline 17 & $5.5 \%$ & $22.6 \%$ & $14 \%(187)$ & $43 \%(23)^{*}$ \\
\hline 18 & $6.1 \%$ & $27.5 \%$ & $12 \%(150)$ & $36 \%(47)^{*}$ \\
\hline 19-20 & $4.4 \%$ & $31.0 \%$ & $16 \%(159)$ & $45 \%(89)^{*}$ \\
\hline
\end{tabular}

The proportion of the number of underage smokers, aged 17 or younger, among all male and female smokers, was $2.9 \%$ for boys and $8.8 \%$ for girls, respectively (data not shown). In addition, the ratio of smoking prevalence between boys and girls in this age group was 3.6 to $1(14.3 \% / 4.0 \%)$, as compared to 10.9 to $1(46.8 \% / 4.3 \%)$ among adult age groups. The proportion of underage to adult smoking rates was three times higher for girls $(4.0 \% / 4.3 \%)$ than for boys $(14.3 \%$ / $46.8 \%)$.

For men, those who graduated middle school had the highest smoking rates, with smoking rates declining with the duration of schooling. Similar patterns were observed for women. Prevalence rates also decreased with income for men, but less clear patterns were observed for women. Low income or less educated men (6-9 years of schooling) had a mean smoking prevalence nearly twice that of the high income or better educated ( 12 years or more). Men who work in blue collar occupations have $50 \%$ higher smoking rates than white collar occupations with service industries in between. For women, different patterns were observed, with service industries having the highest smoking rates, followed by blue collar and white collar.

Table 2 shows that high school age adolescents had smoking prevalence between three to seven times higher if they did not attend school. Similar patterns were seen for those males who finished high school without further educational pursuit, with a threefold increase in their smoking rates. Between ages 17 and 25, male smoking prevalence increased from $22.6 \%$ to $47.7 \%$, the greatest increase of any age group, indicating that substantial smoking initiation took place after age 17 when the individuals left high school.

\section{Ex-smokers}

As shown in table 1 , the prevalence of former smokers was $6.8 \%$ for males and $0.5 \%$ for females, with an overall smoker/ ex-smoker ratio of 6.9. Among men, the rates of former smokers increased continuously with age, and the smoker/ ex-smoker ratio decreased from 26.2 in the 20-29 years to 1.3 in the 70 years or older.

\section{Quantity smoked}

Among current smokers, proportionately more females (14\%) than males $(6 \%)$ were occasional smokers, and, among males, the younger age groups (between the ages of 18-30) had more people smoking occasionally.

Table 3 shows that the mean number of cigarettes smoked per day by daily smokers in 2001 was 17.2 for males and 10.8 for females. In both sexes, the quantity smoked increased with age and peaked at age 45-64, and then declined

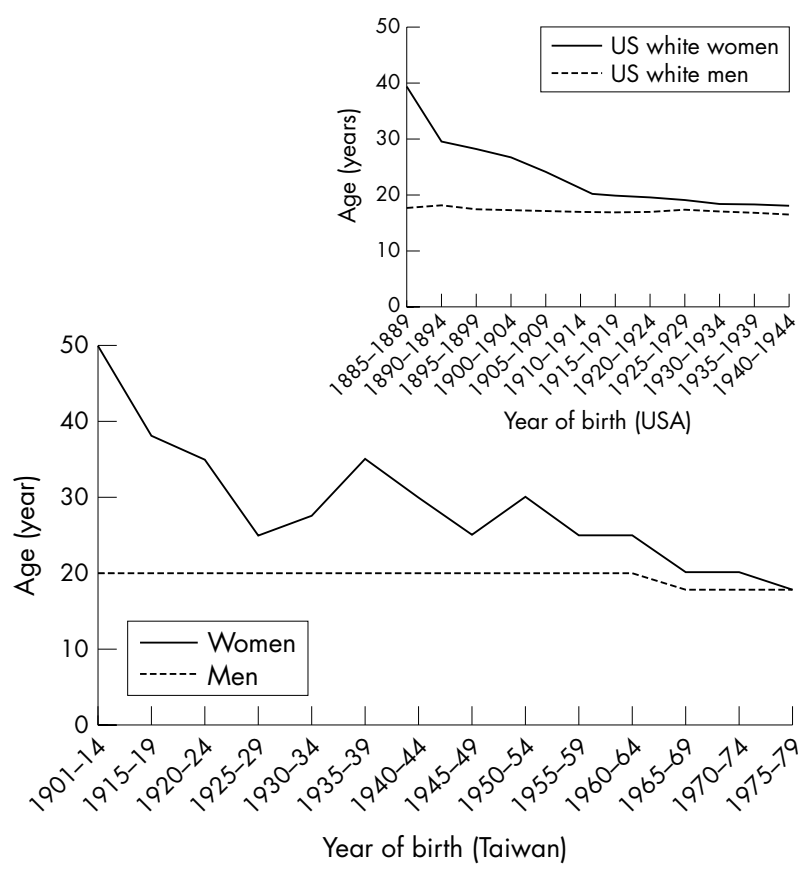

Figure 1 Median age at smoking initiation among people aged 18 or older, by sex and birth cohort in Taiwan based on National Health Interview Survey 2001. Median age at smoking initiation was the age at which one half of smokers in each cohort initiated smoking. For comparison, US smoking initiation age (for white men and women) is plotted at the right upper corner, using the same methodology (USDHSS, ${ }^{12}$ p 75).

\begin{tabular}{|c|c|c|c|c|}
\hline & \multicolumn{2}{|l|}{ Male } & \multicolumn{2}{|l|}{ Female } \\
\hline & No. of cpd & $95 \% \mathrm{Cl}$ & No. of cpd & $95 \% \mathrm{Cl}$ \\
\hline Total & 17.2 & 16.9 to 17.5 & 10.8 & 9.9 to 11.6 \\
\hline \multicolumn{5}{|l|}{ Age } \\
\hline $18-24$ & 13.4 & 12.7 to 14.1 & 6.9 & 5.4 to 8.4 \\
\hline $25-44$ & 17.4 & 17.0 to 17.9 & 10.4 & 9.3 to 11.5 \\
\hline $45-64$ & 18.9 & 18.2 to 19.5 & 13.2 & 11.4 to 15.0 \\
\hline 65 or above & 15.5 & 14.5 to 16.4 & 11.7 & 8.8 to 14.6 \\
\hline \multicolumn{5}{|c|}{ Profession (age 25-64) } \\
\hline White collar & 16.8 & 16.3 to 17.4 & 14.1 & 11.5 to 16.7 \\
\hline Blue collar & 18.4 & 17.7 to 19.0 & 9.6 & 6.2 to 12.9 \\
\hline Service industry & 18.0 & 16.7 to 19.3 & 10.3 & 8.3 to 12.2 \\
\hline
\end{tabular}


afterwards. At the time of smoking the most, middle age adults smoked 19 and 13 cigarettes/day, for males and for females, respectively. Table 3 also shows that quantity smoked is greater for males in blue collar professions than for those in white collar professions, but the reverse is true for females.

\section{Initiation age}

The analysis of birth cohort is portrayed in fig 1 . It shows that the initiation age of smokers, age 18 and older, had declined in the last 20 years for both sexes. Starting with the 19651969 cohorts, the long held median initiation age at 20 for male smokers declined to age 18. For female smokers, the initiation age declined rapidly from 50 years in the 1901-1914 birth cohorts to 30 years in the 1940-1944 cohorts. It then declined again from 25 years in the 1955-1959 cohorts to 20 years old in the 1965-1969 cohorts.

\section{Environmental tobacco smoke exposure}

As shown in table 4, more than half of the total non-smoking population was exposed to ETS at home, and almost $40 \%$ were exposed on a daily basis. Females and those at younger ages tended to have higher exposure. In particular, more than half of non-smoking women of childbearing ages (57-59\%) were exposed, much higher than men in similar age groups. Nearly two thirds of infants and young children ( 11 years or younger) were exposed to ETS at home.

\section{DISCUSSION}

This paper provides an overview of the smoking rates and characteristics of smokers in Taiwan. The persistence of a large gap between high male and low female rates, commonly seen in Southeast Asian countries, ${ }^{14}$ has received limited attention but is worthy of special concern, as it may have played an important role in the shortening in life expectancy observed among males in these countries. ${ }^{15}$

This large sex differential presents special challenges for the development of sex specific strategies for tobacco control. ${ }^{16}{ }^{17}$ For example, having effective or strict workplace smoking policies will discourage more males than females from smoking, as men smoke more than women at work by a factor of 10 or more. ${ }^{18}$ A successful narrowing of the sex gap was achieved in the USA between 1965 (52\% for males and $34 \%$ for females) and $1997-8$ (26\% for males and $22 \%$ for females), ${ }^{19}$ mostly through the reduction in male smoking rates. Studying this experience in reducing male rates would

Table 4 The prevalence of exposure to environmental tobacco smoke at home (excluding smokers) surveyed in Taiwan, 2001 (\%)*

\begin{tabular}{lll}
\hline & $\begin{array}{l}\text { Daily } \\
\text { exposure (\%) }\end{array}$ & $\begin{array}{l}\text { Total (including } \\
\text { occasional exposure) (\%) }\end{array}$ \\
\hline Total & 38.5 & 54.3 \\
Male & 32.8 & 48.8 \\
Age 0-11 & 47.9 & 63.7 \\
$12-17$ & 43.0 & 58.0 \\
$18-24$ & 36.4 & 52.1 \\
$25-44$ & 19.9 & 36.6 \\
$45-64$ & 17.6 & 35.2 \\
65 and over & 23.8 & 37.8 \\
Female & 42.4 & 58.1 \\
Age 0-11 & 47.8 & 64.5 \\
$12-17$ & 42.4 & 59.8 \\
$18-24$ & 42.4 & 58.7 \\
$25-44$ & 41.5 & 57.3 \\
$45-64$ & 41.1 & 55.9 \\
65 and over & 38.4 & 51.3 \\
\hline *Defined in terms of presence of someone smoking at your home, on a \\
daily or someday basis.
\end{tabular}

be valuable, particularly if a mechanism can be developed to accomplish such narrowing in less time than the three decades it took for the USA. Lessons can also be learned from studying why most women do not smoke in Taiwan. It can be argued that girls, more than boys, in Taiwan routinely receive more pressure from society ("smoking is a male behaviour" and "nice girls do not smoke"), ${ }^{20}$ from parents (girls respond more to parental authority), ${ }^{21}$ and from financial constraints. ${ }^{1}$ Knowledge about the factors that have kept smoking rates low for females might be applied to males in Asian countries. For example, through learning how girls responded to pressure, attempts can be made to make smoking more socially unacceptable, to encourage parents to be more assertive in their anti-smoking attitudes, and to raise cigarette prices sharply to limit resources.

The finding that the proportion of underage to adult smoking rates was three times higher for girls than for boys, and the male to female ratio of underage smoking rates was 3.6 to 1 , compared to 11 to 1 in the adults, merits special attention. If this ratio were to continue, smoking rates of adult women in Taiwan are likely to increase substantially in the coming years, and may reach the smoking rates of Japanese women, as they are three times higher than their Taiwan counterparts. ${ }^{2}$ Again, we should carefully study why most women in Taiwan did not smoke and perpetuate the positive attributes.

The observation that staying in schools kept smoking rates low have important implications for resource allocation in tobacco control programmes. The vulnerable groups, such as those not attending high schools or those finishing high schools, traditionally did not receive special attention in Taiwan, and were seldom targeted before they became vulnerable.

Smoking quantity increased with age, reflecting the increasing degree of addiction to cigarettes. ${ }^{22}{ }^{23}$ Most smokers in Taiwan consumed relatively fewer cigarettes than their Western counterparts, with daily smokers averaging less than a pack a day for men and half a pack for women. The US male and female smokers smoked $24 \%$ and 55\% more, respectively. ${ }^{19}$ This characteristic of smokers, currently smoking less, has important public health implications, as there is room to smoke more as the economy improves in Taiwan. The currently reported lower relative risks, such as lung cancer, would increase ${ }^{24}$ if smokers in Taiwan continue past trends of increasing quantity smoked per smoker. ${ }^{10}$ The relative risks of smoking related diseases in Taiwan are also likely to increase with the steadily declining median ages of initiation. ${ }^{25}$ The ages that smokers start smoking in Taiwan are now close to those in the USA ( $18 v 17$ for males, and $20 v$ 18 for females), ${ }^{12}$ The trend of becoming younger in the initiation age in Taiwan is of concern.

An important observation in this study is the low quit rate among males. The ratio of smoker/ex-smoker rates of close to 7 in Taiwan stands in stark contrast to a ratio near 1 in the $\mathrm{USA}^{19}$ indicating a particularly low rate of effective smoking cessation. In Taiwan, surveys found more than $80 \%$ of quitters quit for medical reasons ${ }^{26}$ The rapid decrease in the smoker/ex-smoker ratios with increasing age-for example, 26.2 in the $20-29$ age group decreasing to 1.3 in the age 70 or older-supports the evidence on the importance of a medical reason for quitting. Since the opening of the cigarette market to foreign tobacco companies, Taiwan, like many other Asian countries, has spent much of its efforts in preventing youth from smoking. The sevenfold difference in the ratio of smoker/ex-smoker rates between Taiwan and the USA may be traced to this emphasis on prevention, with relatively little attention to cessation. Future tobacco control programmes not only should make cessation a much higher priority, but also such programmes should aim at the younger age groups, 


\section{What this paper adds}

Taiwan has particularly high male smoking rates and much lower female rates, with a ratio of 11 to 1 . Based on current trends, there is a strong potential for female rates to increase. Taiwan has a low quit rate among males, which reflects a historical emphasis on youth prevention programmes. Women and young children in Taiwan are exposed to high environmental tobacco smoke (ETS) at home. ETS has been socially accepted for decades, but its harmful effects are beginning to manifest.

long before the development of smoking related medical diseases, to reduce the unnecessary pain and suffering.

A large percentage of non-smoking women in Taiwan are exposed to ETS. The $58 \%$ exposure to ETS among nonsmoking women in Taiwan was 4.4 times higher than their counterparts in the USA (13.2\%) as found in the 1994 NHIS study. ${ }^{12}$ Such a high rate of ETS exposure became doubly serious in health risks ${ }^{27}$ when these women actually resided in smaller and more crowded homes than their counterparts in the USA, averaging 1000 square feet per home living with extended families in Taiwan. ${ }^{28}$ The age adjusted lung cancer rate in women has increased by $180 \%$ in the last 30 years in Taiwan, or a $6 \%$ increase per year, with the number of lung cancer deaths increasing by nearly sixfold during this time period. ${ }^{29}$ ETS exposure has been shown to be associated with increased lung cancer in Japanese women, ${ }^{30}$ but the extent to which the high ETS exposure in women in Taiwan was responsible for the rapid increase in female lung cancer has received relatively little attention in the public health literature. ${ }^{31}$

Each day, nearly two thirds of infants, young children, and pregnant women are exposed to ETS. This finding, along with the large percentage of non-smoking women in Taiwan exposed to ETS, appears to reflect a lack of understanding of the associated ETS risks, including lung cancer, heart disease, asthma, sudden infant death syndrome, and other health risks to the fetus and newborns. ${ }^{12}{ }^{27}$ These ETS risks have been publicly accepted by the leading international tobacco companies, ${ }^{32}$ but not the domestic maker of cigarettes, the Monopoly Bureau. Future policies should require the Monopoly Bureau to publicise those ETS risks at home and remedy any such lack of understanding.

In short, typical of most Asian populations, Taiwan has particularly high smoking rates for males and much lower rates for females. These low rates for women are likely to increase and may approximate those of Japanese women, if the current sex ratio of smoking by underage youth continues. The low quit rate among males, the high ETS exposure of women and young children at home, and the sharp increase in smoking rates when students left schools are of particular concern. For male rates to decrease substantially, cessation efforts will need to increase drastically, particularly for younger age groups.

\section{Authors' affiliations}

C P Wen, T Y Cheng, C-C Hsu, Division of Health Policy Research, National Health Research Institute, Taipei, Taiwan

D T Levy, University of Baltimore, Baltimore, and Pacific Institute, Calverton, Maryland, USA

S P Tsai, The University of Texas Health Science Center at Houston, School of Public Health, Houston, Texas, USA

Competing interests: none declared

\section{REFERENCES}

1 Mackay J, Eriksen M. The tobacco atlas. Geneva, Switzerland: World Health Organization, 2002

2 Honjo K, Kawachi I. Effects of marketing liberalisation on smoking in Japan. Tobacco Control 2000;9:193-200.

3 Yu JJ, Mattson ME, Boyd GM, et al. A comparison of smoking patterns in the People's Republic of China with the United States. An impending health catastrophe in the middle kingdom. JAMA 1990;264:1575-9.

4 Yang G, Fan L, Tan J, et al. Smoking in China: findings of the 1996 national prevalence survey. JAMA 1999;282:1247-53.

5 Rani $M$, Bonu S, Jha $P$, et al. Tobacco use in India: prevalence and predictors of smoking and chewing in a national cross sectional household survey. Tobacco Control 2003;12:4.

6 US Department of Health and Human Services. Healthy people 2010. Washington DC: US Government Printing Office, 2000.

7 Centers for Disease Control and Prevention. Percentage of adults who were current, former, or never smokers, + overall and by sex, race, Hispanic origin, age, and education, National Health Interview Surveys, selected years in United States, 1965-2000, 2003. http://www.cdc.gov/tobacco/ research_data/adults_prev/adstatl print.htm (Accessed Dec 16, 2004).

8 Centers for Disease Control and Prevention. Best practices for comprehensive tobacco control program - August 1999. Atlanta, Georgia: US Department of Health and Human Services, Centers for Disease Control and Prevention, Office on Smoking and Health, August, 1999.

9 National Health Research Institutes. National Health Interview Survey (NHIS) in 2001. Bureau of Health Promotion and National Health Research Institutes, 2002. http://nhis.nhri.org.tw.

10 Cheng TY, Wen CP, Tsai MC, et al. The current status of smoking behavior in Taiwan: Data analysis from National Health Interview Survey in 2001 (in Chinese). Taiwan J Public Health 2003;22(6).

11 World Health Organization. Guidelines for controlling and monitoring the tobacco epidemic. Geneva: WHO, 1998

12 US Department of Health and Human Services. Women and health: a report of the Surgeon General. Atlanta, Georgia: US Department of Health and Human Services, Center for Disease Control and Prevention, Office on Smoking and Health, 2001.

13 Shih YT, Hung YT, Chang HY, et al. The design, contents, operation and the characteristics of the respondents of the 2001 National Health Interview Survey in 2001 (in Chinese). Taiwan J Public Health 2003;22:419-30.

14 American Cancer Society. Tobacco control country profiles. Atlanta, Georgia: American Cancer Society, 2000-03.

15 Retherford RD. Tobacco smoking and the sex mortality differential. Demography 1972;9:203-16.

16 Ernster V, Kaufman N, Nichter M, et al. Women and tobacco: moving from policy to action. Bull World Health Organ 2000;78:891-901.

17 Gritz ER, Nielsen IR, Brooks LA. Smoking cessation and gender: the influence of physiological, psychological, and behavioral factors. J Am Med Womens Assoc 1996;51:35-42.

18 Tsai SP, Wen CP, Hu SC, et al. Workplace smoking related absenteeism and productivity costs in Taiwan. Tobacco Control 2005; 14(suppl I):i33-7.

19 Schoenborn CA, Vickerie JL, Barnes PM. Cigarette smoking behavior of adults: United States, 1997-98. Hyattsville, Maryland: National Center for Health Statistics, 2003.

20 Lin FE. An explorative study about young women's smoking behavior in Taipei. Taipei, Taiwan: National Taiwan University, 2001 (Master Thesis).

21 Tyas SL, Pederson LL. Psychosocial factors related to adolescent smoking: a critical review of the literature. Tobacco Control 1998;7:409-20.

22 Radzius A, Gallo JJ, Epstein DH, et al. A factor analysis of the Fagerstrom test for nicotine dependence (FTND). Nicotine Tob Res 2003;5:141-4.

23 John U, Meyer C, Hapke U, et al. Nicotine dependence and lifetime amount of smoking in a population sample. Eur J Public Health 2004;14:182-5.

24 Wen CP, Tsai SP, Chen CJ, et al. The mortality risks of smokers in Taiwanpart I: cause-specific mortality. Prev Med 2004;39:528-35.

25 Liaw KM, Chen CJ. Mortality attributable to cigarette smoking in Taiwan: a 12-year follow-up study. Tobacco Control 1998;7:141-8.

26 Monopoly Bureau. Report from tobacco and alcohol consumption survey in Taiwan area. Taipei, Taiwan: Taiwan Tobacco and Wine Monopoly Bureau, 1964-1996.

27 US Department of Health and Human Services. The health consequences of involuntary smoking. A report of the Surgeon General. Rockville, Maryland: Public Health Service, Centers for Disease Control, 1986 (DHHS Publication No (CDC) 87-8398.).

28 Directorate-General of Budget, Accounting and Statistics. Survey on Residence Status. Directorate-General of Budget, Accounting and Statistics (DGBAS), Executive Yuan, 1992. http://www.dgbas.gov.tw/census n/six/ lue5/HT46232.HTM (Accessed Nov 10, 2004).

29 Department of Health. Vital satistics in Taiwan. Taipei, Taiwan: Department of Health, Executive Yuan, Taiwan, 1975-2002.

30 Hirayama T. Non-smoking wives of heavy smokers have a higher risk of lung cancer: a study from Japan. BMJ (Clin Res Ed) 1981;282:183-5.

31 Ko YC, Lee CH, Chen MJ. Risk factors for primary lung cancer among nonsmoking women in Taiwan. Int J Epidemiol 1997;26:24-31.

32 Philip Morris International. Secondhand smoke. 2004. http:// www.philipmorrisinternational.com/pages/eng/smoking/ Secondhand_smoke.asp (Accessed Nov 10, 2004). 